\title{
Children's healthy and unhealthy food intake related to parental fear of the COVID-19, family communication patterns, and parental controlling feeding practices
}

Kay W. Kim ( $\square$ wkim32@ucmerced.edu )

University of California, Merced

Jan L. Wallander

University of California, Merced

\section{Research Article}

Keywords: COVID-19 fear, parent, child, communication, feeding practices, dietary intake

Posted Date: February 14th, 2023

DOI: https://doi.org/10.21203/rs.3.rs-1236389/v2

License: @ (i) This work is licensed under a Creative Commons Attribution 4.0 International License. Read Full License 


\section{Abstract}

The COVID-19 pandemic in 2020 changed the daily lives of families, including their food environments. We tested a conceptual model of potential influences on children's dietary intake under these conditions. 306 (51\% fathers) parents with children ages 5- 12 were recruited for an online study, where they completed questionnaires to measure fear of COVID-19, family communication patterns, parental controlling feeding practices, and child's healthy and unhealthy food intake. Structural equation modeling was used, including a multigroup analysis to compare mothers and fathers. Parental fear of COVID-19 was positively related to communication patterns, which were positively associated with parental controlling feeding practices. Communication patterns were also linked to child unhealthy food intake, but only for mothers. General family communication patterns play an important role in children's dietary intake. Therefore, it may be useful to help parents adopt general positive parenting approaches to influence their children's healthy development.

\section{Main Text}

A well-balanced healthy diet with adequate nutrients is pivotal for children's mental and physical development [1]. Unhealthy food intake among young children, therefore, is a critical public health concern, given that this not only inhibits overall healthy development but also becomes predictive of chronic diseases later into adulthood such as cardiovascular disease, obesity, and diabetes [2]. However, children's typical dietary intakes are poorly aligned with national dietary guidelines in that their diets are often low in fruits and vegetables and high in discretionary food, which is less healthy or unhealthy [3, 4]. Building healthy eating habits during childhood is crucial as obesity is closely tied to unhealthy eating behaviors and childhood is a prime time to instill healthy lifestyles [2].

While researchers have argued that parents and home environment are key influences in shaping children's food consumption [1], the COVID-19 outbreak in early 2020 appears further to have intensified such impact [5]. Faced with the COVID-19 pandemic, most countries including the US imposed lockdowns and social distancing policies. Workplaces, schools, universities, childcare facilities, as well as nonessential stores had been closed at some point in the year 2020 [6]. Consequently, parents became even more influential in their children's food intake given that families were confined at home and parents served all meals and snacks [7]. Therefore, it was unavoidable that changes would follow in the home food environment and child dietary intake [8].

The COVID-19 pandemic created an upheaval in daily life with numerous associated consequences in the home environment. Parents feared getting exposed to and being infected by the virus, as well as losing loved ones. There were also uncertainties about how this pandemic would unfold and end in the year 2020 [9]. Parents were a vulnerable group during COVID-19 as they tended to report more fear of COVID-19 than their adult counterparts without children [10]. Fear easily co-existed with other mental health issues during the pandemic as people reporting more COVID-19 fear also presented more anxiety and depression symptoms [11]. Fear was amplified during the stressful pandemic and was observed to spread among family members [12,13]. Thus, consideration of parental fear of COVID-19 is crucial for a fuller understanding of the family dynamics during the lockdown and ultimately how this affected children's dietary intake.

Furthermore, stay-at-home orders or lockdowns in 2020 provided a unique context that provided opportunities for family members to communicate and interact with each other in forced proximity [14]. According to the theory of family communication patterns, which is one of the most frequently applied theories in the field, family values and beliefs are reflected verbally through conversation-oriented (CONV) communication and conformity-oriented (CONF) communication [15]. The CONV communication pattern is characterized by unstrained interaction among family members and freedom to voice differing viewpoints. Families high in CONV communication present a fluid family structure and encourage individuality whereas the CONF pattern is marked by the prioritization of family interests above those of individuals and emphasis on children's obedience to authority figures, such as parents.

Previous research has shown that family communication patterns are connected to family health-related behaviors [16]. For instance, families high in CONV communication were more open to discussing health than families high in CONF communication [17]. Also, a previous study with young adults found that families high in CONV communication were more likely to believe that eating nutritious foods is important and engage in consuming low-fat food, fruit, and vegetable. In contrast, families high in CONF communication discuss less about health and engage less in health-promoting behaviors [17]. Thus, these findings support the continued importance of family communication patterns in influencing family health-related behaviors.

As such, among various broader parental factors affecting children's diets, we specifically expect family communication patterns to serve as a vehicle for effective parental feeding practices because feeding practices are based on parent-child communication. Parents express their feeding practices both verbally and non-verbally to children [18]. Likewise, children also express their opinions regarding 
their parents' food choices and feeding practices by making demands, negotiating, and refusing to eat [19]. Similarly, multiple studies have shown that when more food choices were provided to children, they tended to make more unhealthy food choices [20]. In this sense, feeding practices can be viewed as constant juggling between parents and children through communication. Family communication patterns thus would serve as a foundation for parental feeding practices.

One commonly examined feeding practice is parents' controlling feeding, including restriction, pressure to eat, and monitoring. Controlling feeding is known to increase during stressful times [21], such as during the COVID-19 pandemic [22]. It appears that distress from the external factor wears on parents, and they become less responsive to their children's hunger and satiety cues [8, 23], which should otherwise be the prime stimulus for feeding. Thus, it is likely that parental controlling feeding practices may have been expressed to a greater degree during the early phase of the COVID-19 pandemic.

There is growing literature that broader parental factors are equally as or more important than specific feeding practices in influencing children's food intake [24]. For instance, authoritative parenting styles that focus on warmth and provide control seemed to promote healthy eating among children [25], whereas permissive parenting was associated with children's eating fewer fruits and vegetables [26]. Furthermore, previous research suggested that the proximal feeding practices are reflective of broader parental styles such that permissive general parenting is related to increased use of restriction of certain foods [27]. As the pandemic was unprecedented, we argue that broader family factors could be more influential in the family food environment than before.

While it is evident that the COVID-19 pandemic changed the food consumption of families, there have been mixed reports on children's healthy and unhealthy food intake during the pandemic. Some have reported increased intake of both processed foods and fresh foods in the home [8] and others have reported only an increase in junk food [22]. More information is warranted on children's different types of dietary intake during the pandemic to inform interventions to promote healthy and nutritious eating among children, even as the acute effects of the pandemic have dissipated for many people.

Mothers and fathers have shown different interactions with their children and feeding practices [28, 29]. The work-from-home policies and lock-down orders provided an unprecedented environment where both parents stayed home. Thus, it is expected that fathers could exert more influence on child-rearing during the pandemic. Yet, to our knowledge, no study has sought to understand parental gender differences in family communication during the pandemic. In terms of parenting around food, one study reported no differences between [30]. We need more evidence about parental factors linked to child food intake to devise more tailed intervention strategies to foster healthier intake.

Reflecting on the discussion above, we propose that the fear of the COVID-19 pandemic influenced how families communicate and interact with each other and this ultimately had indirect, if not direct, effects on children's food intake. Thus, the current study aimed to investigate how broader factors such as parental fear of COVID-19 and family communication patterns, and more proximal parental controlling feeding practices were related to children's healthy and unhealthy food consumption when family life changed drastically during the first few months of the pandemic. Given that fathers on average became more engaged in parenting during this unique period due to spending more time at home, we also examined if there were distinctive differences between mothers and fathers regarding the food intake of their children.

The conceptual model depicted in Fig. 1 identifies hypothesized relationships among parental fear of COVID-19, family communication patterns, parental controlling feeding practices, and child's dietary intake, which leads to two hypotheses we specifically tested here:

H1. Broader family factors such as parental fear of COVID-19 and family communication patterns are related more strongly to children's healthy and unhealthy food intake than parental controlling feeding practices.

H2. Mothers' compared to fathers' family communication patterns and feeding practices have stronger associations with children's food intake.

\section{Methods}

Institutional Review Board from the University of California, Merced approved the study, which was conducted in compliance with ethical standards in the treatment of the participants between August 13, 2020, and August 21, 2020 (IRB approval ID: UCM2020-52).

\section{Participants}


The study included 306 parents (51\% fathers), satisfying common recommendations for sample size requirements [31], given 31 parameters and 8 variables in the structural equations modeling (SEM) of the proposed model. Eligibility requirements were participants being above 18 years of age and proficient in English, residing in the US, and having at least one child between 5 and 12 years of age (Mean child age $=8.71, \mathrm{SD}=1.97$ ). Mothers and fathers in the current study were from different families. When a participant had more than one child, he or she was asked to select one child in the age range to complete the questionnaire. Demographic information is presented in Table 1.

\section{Procedures}

Participants were recruited using a Facebook snowball sampling method, which was selected because it provided easy access to the target population at a lower cost than alternatives [32]. Moreover, the number of cases detected by Facebook is higher than the traditional snowball sampling method [33]. Participants saw threads on Facebook and clicked the link for the study, which led to the Google Survey form through which the study was administered. To start, participants were presented with a description of the study and informed consent. After indicating written consent, they answered questions online, using their smartphone or computer for approximately 20-30 minutes. The first 100 participants were compensated with a \$10 Amazon e-gift card, and the remainder with a \$5 card.

\section{Measures}

\section{Fear of COVID-19}

Participants were asked to indicate their level of agreement with seven items addressing fear of COVID-19, such as "I am most afraid of COVID-19" and "It makes me uncomfortable to think about COVID-19," used in previous research [34]. Responses were recorded on a fivepoint Likert scale $(1=$ "strongly disagree" to $5=$ "strongly agree"). A total sum across items was calculated, with higher scores indicating higher levels of fear of COVID-19. Internal consistency for this sample was $a=.80$.

\section{Parent-child communication}

Parent-child communication was evaluated with the Revised Family Communication Pattern Instrument - Parent Version (RFCP) [35], which has been developed to measure family communication according to the Family Communication Patterns Theory [36]. The RFCP consists of 26 items measuring two underlying dimensions of family communication pattern, using a Likert-scale ( $1=$ "strongly disagree" to $5=$ "strongly agree"): (1) conversation-oriented (CONV) family communication (15 items) such as "I often ask my child's opinion when the family is talking about something" and "My child and I often have long, relaxed conversations about nothing in particular;" and (2) conformity-oriented (CONF) family communication (11 items) such as "When my child is at home, it is expected to obey the parents' rules" and "In our home, the parents usually have the last word." Scores were calculated as the mean item score separately for each communication dimension, with a higher score indicating a stronger presence of that dimension. Internal consistency for this sample was $\mathrm{a}=.91$ for CONV and .80 for CONF communication.

\section{Parents' controlling feeding practices}

The parental controlling feeding practices with the child were assessed, using three of dimensions the Child Feeding Questionnaire [37], including (1) monitor (e.g., "How much do you keep track of the sweets that your child eats?"), (2) restriction (e.g., "I have to be sure that my child does not eat too much of his or her favorite foods"), and (3) pressure to eat (e.g., "My child should always eat all of the food on his or her plate"). Responses were made on 5-point scale, with anchors from "never" to "always" for the monitoring items and from "disagree" to "agree" for the restriction and the pressure to eat items. Items were subjected to a confirmatory factor analysis (CFA), supporting using six items (see Table 3 for factor loadings) to indicate the latent variable of controlling feeding practices. Internal consistency for these was $a=.81$.

\section{Child's dietary intake}

Using items from the California Health Interview Survey Diet Screener, parents were asked about the child's dietary intake of two food categories commonly used to mark healthy intake (fruits and vegetables) and four used to mark unhealthy intake (juice, soda, sweets, and fast-food consumption) [38]. These are food categories commonly used in survey research to mark healthy and unhealthy diet intake [39, 40,41]. Questions ask about the number of servings the child consumed yesterday for each food category, with responses ranging from " 0 " to "more than 8 servings." The exception was for fast-food consumption, for which the period was last week. Servings 
were self-defined by parents and considered to be the child's regular portion of the food. Items were subjected to CFA to confirm using two and four items (see Table 3 for factor loadings) to measure the latent variables of healthy intake and unhealthy intake, respectively. Internal consistency for healthy intake was $\alpha=.60$ and unhealthy intake $a=.80$.

\section{Race/ethnicity}

Participants indicated which one or more of eight racial/ethnic categories described the child from the following: American Indian or Alaska Native, Asian, Black/African American, Caucasian/White, Hispanic/Latino, Middle Eastern, Mixed and Multi-racial, or other race and ethnicity. Using the Census classification approach, the child was classified as Asian or Latino if so indicated, regardless of other racial/ethnic indications.

\section{Statistical Analysis}

IBM SPSS Statistics 28 was used for descriptive statistics and Mplus for structural equations model (SEM) analysis. To assess the construct validity of the measurement models for three latent variables of controlling feeding practices and child's healthy and unhealthy dietary intakes, separate CFAs. The resulting measurement models had adequate fits for inclusion in the SEM.

An SEM path analysis was conducted first for the total sample. Subsequently, a multi-group SEM analysis was conducted with the father and mother subsamples. The child's gender was entered as a control variable in the path analysis. Additionally, the structural models of indirect effects of family communication and parental controlling feeding practices between parental COVID-19 fear and children's healthy and unhealthy food intake were tested using maximum likelihood estimation and a bias-corrected bootstrapping procedure with 1000 iterations. The bootstrapping method can correct bias and thus give more accurate estimations [42]. The indirect effect is considered statistically significant if zero is not contained in the $95 \%$ confidence interval. Multi-group path analysis was completed also to test for father and mother group differences in structural parameters of the indirect effect model.

To examine the goodness of fit of the model, the comparative fit index (CFI), Tucker-Lewis index (TLI), and root mean square error of approximation (RMSEA) were assessed. Adequate fit for parsimonious SEM has been identified as CFI $\geq 0.90, T L I \geq 0.90$, and RMSEA $\leq$ 0.10 [43]. A value of $a=0.05$ was set for statistical significance. Missing data was implemented under maximum likelihood estimation [44].

\section{Results}

Descriptive information about the participants is presented in Table 1, and the study variables are in Table 2. About the same proportion of about two-thirds of fathers $(69 \%)$ and mothers $(66 \%)$ reported that they are responsible for feeding their child "about half the time" or more (Table 1). Independent samples t-tests indicated there were no significant differences between fathers and mothers reporting use of the family communication or controlling feeding practices patterns (Table 2). Children were reported to consume approximately three servings a day of both fruits and vegetables. They were also reported to consume between two and three servings each of sweets, juice, and soda per day and three servings of fast food per week. Correlations among variables as well as factor loadings for the latent variable are presented in Table 3. 


\begin{tabular}{|c|c|}
\hline Variable & $\%$ \\
\hline \multicolumn{2}{|l|}{ Child's gender } \\
\hline Boy & 67.40 \\
\hline Girl & 32.60 \\
\hline \multicolumn{2}{|l|}{ Child's race } \\
\hline Asian & 7.10 \\
\hline Black & 16.45 \\
\hline Latinx & 6.13 \\
\hline White & 66.77 \\
\hline Other & 3.55 \\
\hline \multicolumn{2}{|l|}{ Respondent's relationship to the child } \\
\hline Biological father & 50.32 \\
\hline Biological mother & 48.06 \\
\hline Adoptive father & 0.97 \\
\hline Adoptive mother & 0.65 \\
\hline \multicolumn{2}{|l|}{ Father's educational level } \\
\hline 8 th grade or less & 0.63 \\
\hline High school graduate or GED & 7.55 \\
\hline Some college or 2-year degree & 35.85 \\
\hline 4-year college graduate & 49.69 \\
\hline More than a 4-year college degree & 6.29 \\
\hline \multicolumn{2}{|l|}{ Mother's educational level } \\
\hline 8 th grade or less & 0.66 \\
\hline High school graduate or GED & 4.64 \\
\hline Some college, or 2-year degree & 32.19 \\
\hline 4-year college graduate & 48.58 \\
\hline More than a 4-year college degree & 13.93 \\
\hline \multicolumn{2}{|l|}{ Father's feeding involvement ${ }^{a}$} \\
\hline Never & 5.70 \\
\hline Seldom & 25.30 \\
\hline About half the time & 41.80 \\
\hline Most of the time & 24.70 \\
\hline Always & 2.50 \\
\hline Mother's feeding involvement ${ }^{a}$ & \\
\hline
\end{tabular}

a Response to the question "when your child is at home, how often are you responsible for feeding him or her?" 


\begin{tabular}{|l|c|}
\hline Variable & $\%$ \\
\hline Never & 3.30 \\
\hline Seldom & 30.70 \\
\hline About half the time & 29.30 \\
\hline Most of the time & 26.00 \\
\hline Always & 10.70 \\
\hline a Response to the question "when your child is at home, how often are you responsible for feeding him or her?" \\
\hline
\end{tabular}


Table 2

Descriptive statistics for study variables for total sample and father and mother subsamples

Mean (SD)

Scale Total)

Parental fear of COVID-19a

Family Communication Patterns ${ }^{b}$

Conversation-oriented communication

Conformity-oriented communication

Parental feeding practice - Restriction ${ }^{\mathrm{c}}$

Child's sweets intake

Child's high-fat food intake

Child's favorite food intake

Parental feeding practice - Pressure to eat ${ }^{c}$

To eat enough

Parental feeding practice - Monitoring ${ }^{\mathrm{d}}$

Child's snack intake

Child's sweets intake

Child's healthy food intake

Fruit $^{\mathrm{e}}$

Vegetables $^{\mathrm{e}}$ (green salad, green beans, or potatoes)

Child's unhealthy food Intake

Sweets ${ }^{\mathrm{e}}$

Fast-food

Juice $^{\mathrm{e}}$

Soda $^{f}$
$1-5$

$1-5 \quad 3.05(1.19)$

$1-5 \quad 3.08(1.07)$
Fathers

22.20

(5.06) t-test

Mothers

$\begin{array}{ll}21.96 & \mathrm{t}(293)=-.42, p \\ (4.95) & =.67\end{array}$

$=.67$

$\begin{array}{lllll}1-5 & 3.21(0.69) & 3.15(0.68) & 3.28(0.70) & \mathrm{t}(308)=1.69, p=.92 \\ 1-5 & 2.96(0.62) & 3.02(0.64) & 2.89(0.59) & \begin{array}{l}\mathrm{t}(308)=-1.81, p \\ =.07\end{array}\end{array}$


Table 3

Correlations and factor loadings among variables in the total sample

\begin{tabular}{|c|c|c|c|c|c|c|c|c|c|c|c|c|c|c|c|c|}
\hline & & 1 & 2 & 3 & 4 & 5 & 6 & 7 & 8 & 9 & 10 & 11 & 12 & 13 & 14 & 15 \\
\hline $\begin{array}{l}\text { Parental fear of } \\
\text { COVID-19 }\end{array}$ & 1 & & & & & & & & & & & & & & & \\
\hline $\begin{array}{l}\text { Communication } \\
\text { Pattern }^{a}\end{array}$ & 2 & .66 & & & & & & & & & & & & & & \\
\hline $\begin{array}{l}\text { Communication } \\
\text { Pattern }^{\text {b }}\end{array}$ & 3 & .60 & .53 & & & & & & & & & & & & & \\
\hline $\begin{array}{l}\text { Parental } \\
\text { restriction }\end{array}$ & 4 & .35 & .54 & .41 & & & & & & & & & & & & \\
\hline $\begin{array}{l}\text { Parental } \\
\text { restriction }^{d}\end{array}$ & 5 & .44 & .61 & .41 & .60 & & & & & & & & & & & \\
\hline $\begin{array}{l}\text { Parental } \\
\text { restriction }\end{array}$ & 6 & .37 & .47 & .46 & .49 & .47 & & & & & & & & & & \\
\hline $\begin{array}{l}\text { Parental } \\
\text { pressure }\end{array}$ & 7 & .49 & .50 & .39 & .30 & .35 & .32 & & & & & & & & & \\
\hline $\begin{array}{l}\text { Parental } \\
\text { monitoring }\end{array}$ & 8 & .35 & .45 & .46 & .29 & .31 & .36 & .36 & & & & & & & & \\
\hline $\begin{array}{l}\text { Parental } \\
\text { monitoring }\end{array}$ & 9 & .33 & .45 & .39 & .29 & .27 & .34 & .30 & .41 & & & & & & & \\
\hline $\begin{array}{l}\text { Child's fruit } \\
\text { intake }\end{array}$ & 10 & -.05 & -.04 & .08 & -.05 & -.04 & .02 & .10 & .05 & .01 & & & & & & \\
\hline $\begin{array}{l}\text { Child's } \\
\text { vegetable } \\
\text { intake }\end{array}$ & 11 & -.07 & -.10 & .07 & -.06 & -.04 & .00 & .08 & .00 & .05 & .39 & & & & & \\
\hline $\begin{array}{l}\text { Child's sweets } \\
\text { intake }\end{array}$ & 12 & -.01 & -.08 & .19 & .05 & .01 & .02 & .10 & .06 & -.01 & .32 & .35 & & & & \\
\hline $\begin{array}{l}\text { Child's juice } \\
\text { intake }\end{array}$ & 13 & .07 & -.02 & .25 & .00 & -.01 & .05 & .21 & .09 & .10 & .35 & .43 & .47 & & & \\
\hline $\begin{array}{l}\text { Child's soda } \\
\text { intake }\end{array}$ & 14 & .00 & -.16 & .22 & -.04 & -.05 & -.02 & .01 & .00 & .02 & .38 & .45 & .44 & .48 & & \\
\hline $\begin{array}{l}\text { Child's fast- } \\
\text { food intake }\end{array}$ & 15 & -.10 & -.19 & .19 & -.08 & -.08 & .05 & .03 & .02 & .01 & .34 & .33 & .46 & .45 & .42 & \\
\hline \multicolumn{17}{|l|}{$\begin{array}{l}\text { Factor } \\
\text { Loadings }\end{array}$} \\
\hline $\begin{array}{l}\text { Parental } \\
\text { controlling } \\
\text { feeding } \\
\text { practices }\end{array}$ & & & & & {$[.65$} & .70 & .62 & .55 & .54 & $.52]$ & & & & & & \\
\hline $\begin{array}{l}\text { Child's healthy } \\
\text { food intake }\end{array}$ & & & & & & & & & & & {$[.68$} & $.60]$ & & & & \\
\hline $\begin{array}{l}\text { Child's unhealthy } \\
\text { food intake }\end{array}$ & & & & & & & & & & & & & {$[.65$} & .70 & .72 & $.65]$ \\
\hline
\end{tabular}

Note. All correlations and factor loadings in bold $p<.05$. All correlations are controlled for child's gender. CONV $=$ Conversation-oriented, CONF = Conformity-oriented

a CONV communication pattern

${ }^{b}$ CONF communication pattern 
${ }^{\mathrm{c}}$ parental restriction of sweets

${ }^{d}$ parental restriction of high-fat food

e parental restriction of favorite food

${ }^{f}$ parental monitoring of sweets intake

${ }^{g}$ parental monitoring of snack intake

\section{Structural Model For The Total Sample}

Results from the path analysis tested with SEM on the total sample are shown in Fig. 2 . This resulted in a satisfactory fit with the data $(\mathrm{CFI}=0.92, \mathrm{TLI}=0.90$, RMSEA $=0.07)$. Parental fear of COVID-19 was positively associated with both CONV and CONF family communication patterns but did not show an association with either children's healthy or unhealthy food intake. Both CONV and CONF family communications were positively related to parental controlling feeding practices. While CONV communication was inversely related to children's unhealthy food consumption, CONF was positively associated with children's unhealthy dietary intake. Parental controlling feeding practices did not have associations with children's dietary intake.

T: Total sample, F: Fathers, M: Mothers.

\section{Structural Model For Fathers And Mothers}

The multi-group testing resulted in slightly reduced fit $(\mathrm{CFI}=0.89, \mathrm{TLI}=0.87, \mathrm{RMSEA}=0.08)$, which is typically due to the smaller sample size when sub-samples are tested. However, based on the satisfactory fit from the total sample and RMSEA at 0.08, the multi-group model fits the data sufficiently well that it should be informative to examine differences between fathers and mothers.

In the first iteration of implementing the multi-group model, analysis of the mothers produced a non-significant negative residual variance for one observed variable (child's vegetable intake). This situation is common in SEM when there is little-to-no variation across individuals, and a solution is to fix this variation to zero and remove the negative variance from the model [45]. With this adjustment, the model properly estimated all parameters. This multi-group analysis examined whether parameters differed significantly from zero and enabled us to explore differences in significant patterns between fathers and mothers.

As shown in Fig. 2, both fathers and mothers had similar associations in that their fear of COVID-19 was positively related to communication patterns, and communication patterns were also positively related to their controlling feeding practices. The notable difference was witnessed when only mothers' CONV communication pattern was negatively and mothers' CONF communication was positively linked to children's unhealthy eating.

\section{Indirect Pathways}

We conducted further analysis related to the indirect effects of family communications and parental controlling feeding practices between parental fear of COVID-19 and children's healthy and unhealthy food intake. As shown in Table 4, both CONV and CONF family communication patterns had significant indirect effects on children's unhealthy dietary intake. Specifically, CONV family communication pattern mediated between parental COVID-19 fear and children's unhealthy food intake in the negative direction whereas CONF family communication did in the positive direction. Also, as shown in Table 4, only mothers' CONV and CONF communication carried an indirect effect between COVID-19 fear and children's unhealthy food intake. 
Table 4

Standardized Estimates of Indirect Effects, Standard Errors, and 95\% Bias-Corrected Bootstrap Confidence Intervals.

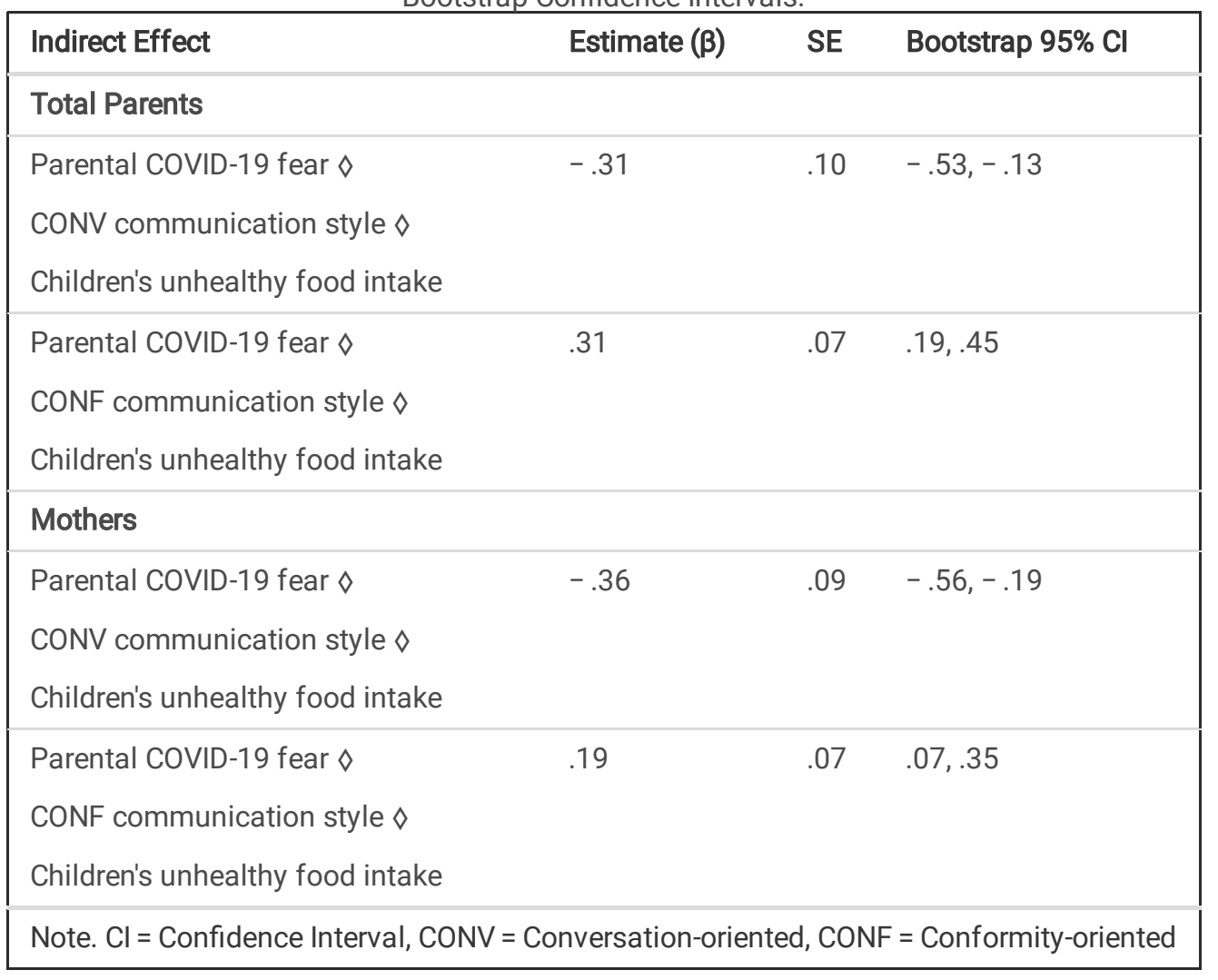

\section{Discussion}

The current study aimed to understand how parental fear of COVID-19, family communication patterns, parental controlling feeding practices, and children's dietary intake were associated according to a conceptual model among American families with young schoolage children during the unique first few months of the COVID-19 pandemic. We found significantly positive associations between parental fear of COVID-19 and both CONV and CONF family communication patterns. Both communication patterns in turn were positively associated with parental controlling feeding practices. Finally, CONV communication pattern was associated with reduced unhealthy food intake in children, while CONF communication was related to increased unhealthy food consumption. For the most part, these associations occurred for both mothers and fathers, but they differed in in a few respects. Fathers' communication patterns were not related to children's food intake, whereas mothers' CONV pattern was negatively and CONF pattern was positively associated with children's unhealthy food intake. Moreover, we found that COVID-19 fear among mothers was indirectly associated with children's unhealthy diet through a link with CONV and CONF communications, where specifically more CONV communication and less CONF communication were associated with reduced food intake in children.

The consistently positive association between parental fear of COVID-19 and both types of family communication patterns revealed that when parents fear COVID-19 more, they are more likely to actively engage in communicating with their children in various ways. Past research identified families that are high in both CONV and CONF orientation as "consensual," which is characterized by a focus on each other's needs and wants [46]. In these families, while open discussion of a wide variety of topics is highly encouraged, each family member's feelings about those topics are ultimately aligned to be congruent and consensual with family beliefs and values [47]. Under the initial pandemic phase, we could argue that parents are very interested in their children's feelings and thoughts to ensure they adapt to the changing conditions. At the same time, parents have the final say on the decisions and expect their children to follow their direction as a team to stay healthy and safe when these appear threatened.

The finding that both CONV and CONF family communications were related to increased parental use of controlling feeding tactics adds to the previous research that family communication patterns affect health attitudes and outcomes [14]. Although COVID-19 had a toll on families, it also had silver linings in that families spent more time together at home, providing opportunities to increase family bonds [48]. Some parents sought to provide structure in the meal environment as they shared meals more frequently with children [23]. It could be that parental controlling feeding practices of monitoring and restricting the discretionary food items and pressuring the child to eat

Page 11/17 
enough were of high value during the first phase of the pandemic. During this time, parents may have felt the need to ensure their children's healthy development under abnormal, even threatening, circumstances.

Parents' controlling feeding practices are considered to hinder children from developing their own food preferences and self-control, resulting in children's reduced diet quality $[49,50,51]$. Also, a recent meta-analysis concluded that pressure to eat overall had a significant negative association with children's healthy intake [52]. However, our study did not find significant direct nor indirect effects involving parental controlling feeding practices on children's healthy or unhealthy dietary intake. One potential explanation is that there are many other important factors influencing children's eating, including types of meals and snacks, family demographics such as a number of siblings, cultural differences, and child food preferences, that are influenced by specific food-related practices.

While we did not find significant effects involving parental controlling feeding practices, we found associations indicating two indirect effects through CONV and CONF communication patterns. Specifically, CONV communication negatively mediated whereas CONF communication positively mediated the relationship between parental COVID-19 fear and children's unhealthy food intake. The positive indirect effect of CONF communication to children's unhealthy food intake suggests that this type of rigid communication of expecting children to follow their parents' direction may interfere with children's diet quality. Similarly, increased CONV communication, which emphasizes open and honest communication among family members, significantly correlated with children's decreased unhealthy food intake, suggesting that bi-directional communication and a positive interaction climate in the family and similar parenting behaviors may affect children's food intake [24]. Thus, this study suggests that broader family factors may exert more influence on children's diets than specific food-focused feeding practices, which was consistent with our Hypothesis 1 and prior research [24].

Furthermore, we found no associations with children's healthy food intake, which could suggest that the influences of parental and family factors are more salient in health-risk behaviors, such as unhealthy eating than in health-promoting behaviors, such as healthy eating [24]. Alternatively, families adopted more distinctive eating patterns around unhealthy food in general during the pandemic. Indeed, studies have reported that families were more likely to reach for snacks or comfort foods due to the increased availability when spending more time at home or in response to stress or boredom during this time [53,54]. Thus, we argue that family and parental factors are presented differently depending on the types of food, as supported by our Hypothesis 2 .

The COVID-19 pandemic opened the opportunity for fathers to become more involved in caretaking, and the majority of the current sample of fathers indicated that they were involved in the feeding of their children. Nonetheless, the multi-group analysis revealed that mothers' communication patterns were more prominent correlates of children's unhealthy food intake. Although mothers and fathers in our sample are from different households and we cannot compare the direct impact on children, we argue that there are parent-gender differences, reflecting our Hypothesis 2. The fathers' COVID-19 fear was linked to CONV and CONF communication, which were also related to their controlling feeding practices, but neither was connected with children's eating behaviors. This pattern of findings suggest that fathers contribute to the family's emotional climate, but mothers are more likely to influence children's dietary intake through their communication pattern, as primarily mothers make decisions about grocery shopping, food preparation, or meal plan [55].

\section{Limitations}

Among the limitations of this study is that the sample volunteered to participate in response to a Facebook thread. Given the focus of the study, many parents presumably volunteered because of interest in what the study addressed, possibly creating a biased sample that may not represent all parents. Furthermore, our sample was over-represented with educated parents who had access to the internet and time flexibility to participate, likely also limiting generalization. Moreover, the experience of the COVID-19 pandemic may differ depending on the infection rate and the government response in the location of the participants, which varied considerably even within the United States. We were unable to examine such regional variations here. Finally, the causal relationships among the variables cannot be determined due to the observational study design. Notwithstanding these limitations, this is the first study we are aware of that illuminates the potential mechanism by which family dynamics may influence children's dietary intake during the unique first few months of the COVID-19 pandemic.

\section{Conclusions}

Despite that we are into the 3rd year since the outbreak of COVID-19, this study where the data was collected in 2020, still sheds light on understanding family dynamics around child food intake. COVID-19 is not expected to be the last worldwide pandemic. Likewise, there are intensifying natural disasters due to climate change that may also exert similar effects on the family environment [56]. Furthermore, the pandemic has changed our lives deeply, and these effects will certainly linger in children's and parents' lives. Parents both knowingly 
and unknowingly share the family context in the household during stressful times. Therefore, we need to recognize the burden that COVID-19 had and may continue to have on the multiple family dynamics around the dietary intake. These results support the need for providing practical help to strengthen family coherence and resilience and promote family well-being, which should create numerous positive cascades in family lives, including in the food environment. Broad approaches to support parents to practice advanced parenting skills should be identified. More research, especially longitudinal studies, will help us better understand what constitutes advantageous family food environments and how to foster these for children's optimal health and well-being.

\section{Summary}

The COVID-19 pandemic has caused abrupt changes in the daily lives of most families, including their food environments. Fear of COVID-19 and family communication patterns are hypothesized to influence parental feeding practices and ultimately children's intake of healthy as well as unhealthy foods. Based on a conceptual model of direct and indirect effects among these variables, we test these hypotheses in an observational cross-sectional design.

306 parents (51\% fathers) with children in the age range 5-12 years were recruited via a Facebook snowball sampling method. They completed questionnaires online to measure fear of COVID-19, conversation- and conformity-oriented family communication patterns, and parental controlling feeding practices. In addition, they reported on the child's intake of food categories marking healthy (fruits and vegetables) and unhealthy (juice, soda, sweets, fast foods) diets. The conceptual model was analyzed with structural equation modeling, including a multi-group analysis to discern differences between mothers and fathers.

There were statistically significant positive associations between parental fear of COVID-19 and both conversation and conformity family communication patterns, both of which in turn were positively associated with parental controlling feeding practices. Conversation communication pattern was associated with reduced unhealthy food intake in children. For the most part, these associations occurred for both mothers and fathers. However, whereas fathers' communication patterns were not related to children's food intake, mothers' conversation pattern was negatively, and conformity pattern was positively, associated with children's unhealthy food intake.

COVID-19 has had a profound impact on families, including children's dietary intake. These results underscore that general family patterns play an important role in children's dietary intake. Therefore, it may be useful to help parents adopt general positive parenting approaches to influence their children's healthy development, including dietary intake.

\section{Declarations}

Author Contribution: KWK designed the study, contributed to the data collection, performed the statistical computation, and wrote the manuscript in consultation with JLW. JLW supervised the study. All authors read and approved the final manuscript.

Funding: This study was funded by UC Merced.

\section{Compliance with Ethical Standards}

The authors declare that they have no conflict of interest.

Informed consent was obtained from all individual participants included in the study.

Institutional Review Board (approval ID: UCM2020-52) approved the study.

\section{References}

1. Ogata BN, Hayes D (2014) Position of the academy of nutrition and dietetics: Nutrition guidance for healthy children ages 2 to 11 years. J Acad Nutr Diet. doi:10.1016/j.and.2014.06.001

2. Sahoo K, Sahoo B, Choudhury AK, Sofi NY, Kumar R, Bhadoria SA (2015) Childhood obesity: causes and consequences. J Family Med Prim Care. doi:10.4103/2249-4863.154628

3. Batis C, Aburto TC, Sanchez-Pimienta TG, Pedraza LS, Rivera JA (2016) Adherence to dietary recommendations for food group intakes is low in the Mexican population. J Nutr. doi:10.3945/jn.115.219626

Page $13 / 17$ 
4. Ogata BN, Hayes D (2014) Position of the academy of nutrition and dietetics: Nutrition guidance for healthy children ages 2 to 11 years. J Acad Nutr Diet. doi:10.1016/j.and.2014.06.001

5. Weeland J, Keijsers L, Brange S (2021) Introduction to the special issue: parenting and family dynamics in times of the COVID-19 pandemic. Dev Psychol. doi: 10.1037/dev0001252

6. Koh D (2020) Covid-19 lockdowns throughout the world. Occup Med. doi: 10.1093/occmed/kqaa073

7. Karki U, Dhonu G, Kunwar AR. Parenting during the COVID-19.JNMA J Nepal Med Assoc. doi: 10.31729/jnma.5319

8. Adams EL, Caccavale LJ, Smith D, Bean MK (2020) Food insecurity, the home food environment, and parent feeding practices in the era of COVID-19. Obes. doi:10.1002/obby22996

9. Heiat M, Heiat F, Halaji M, Ranjbar R, Marvasti ZT, Yaali-Jahromi E, Azizi MM, Morteza Hosseini S, Badri T (2021) Phobia and fear of COVID-19: origins, complications and management, a narrative review. Ann Ig. doi:10.7416/ai.2021.2446

10. Carroll N, Sadowski A, Laila A, Hruska V, Nixon M, Ma DW, Haines J (2020) The impact of COVID-19 on health behavior, stress, financial and food security among middle to high income Canadian families with young children. Nutrients. doi:10.3390/nu12082352

11. Fitzpatrick KM, Harris C, Drawve G (2020) Fear of COVID-19 and the mental health consequences in America. Psychol Trauma. doi:10.1037/tra0000924

12. Jiao WY, Wang LN, Liu J, Fang SF, Jiao FY, Pettoello-Mantovani M, Somekh E (2020) Behavioral and emotional disorders in children during the COVID-19 pandemic. Eur Pediatr Assoc. doi:10.1016/j.jpeds.2020.03.013

13. Suffren S, Dubois-Comtois K, Lemelin J, St. Laurent D, Milot T (2021) Relations between child and parent fears and changes in family functioning related to COVID-19. Int J Environ Res Public Health. doi:10.3390/ijerph18041786

14. Hall ED, Earle K, Silversone J, Immel M, Carlisle M, Campbell N (2022) Changes in family communication during the COVID-19 pandemic: the role of family communication patterns and relational distance. Commun Res. 10.1080/08824096.2021/2025045

15. Koerner AF, Schrodt P (2014) An introduction to the special issue on family communication patterns theory. J Fam Commun. doi:10.1080/15267431.2013.857328

16. Campbell-Salome G, Rauscher EA, Freytag J (2019) Patterns of communication about family health history: exploring differences in family types, age, and sex. Health Edu Behav. doi:10.1177/1090198119853002

17. B-W EA TA (2013) The role of family communication in individual health attitudes and behaviors concerning diet and physical activity. Health Commun. doi: 10.1080/10410236.2021.674911

18. Rodgers RF, Paxton SJ, McLean SA, Campbell KJ, Wertheim EH, Skouteris H, Gibbens K (2014) Maternal negative affect is associated with emotional feeding practices and emotional eating in young children. Appetite. doi:10.1016/j.appet.2014.05.022

19. Holsten JE, Deatrick JA, Kumanyika S, Pinto-Martin J, Compher CW (2012) Children's food choice process in the home environment. A qualitative descriptive study. Appetite. doi:10.1016/j.appet.2011.09.002

20. Papaioannou MA, Cross MB, Power TG, Liu Y, Qu H, Shewchuk RM et al (2013) Feeding style differences in food parenting practices associated with fruit and vegetable intake in children from low-income families. J Nutr Educ Behav. doi:10.1016/j.jneb.2013.05.007

21. Berge JM, Tate A, Trofholz A, Fertig AR, Miner M, Crow S, Neumark-Sztainer D (2017) Momentary parental stress and food-related parenting practices. Pediatrics. doi:10.1542/peds.2017-2295

22. Bin Zarah A, Enriquez-Marulanda J, Andrade JM (2020) Relationship between Dietary Habits, Food Attitudes and Food Security Status among Adults Living within the United States Three Months Post-Mandated Quarantine: A Cross-Sectional Study. Nutr. doi:10.3390/nu12113468

23. Jansen E, Thapaliya G, Aghababian A, Sadler J, Smith K, Carnell S (2021) Parental stress, food parenting practices and child snack intake during the COVID-19 pandemic. Appetite. doi:10.1016/j.appet.2021.105119

24. Kim KW, Wallander JL, Felt JM, Elliott MN, Schuster MA (2019) Associations of parental general monitoring with adolescent weightrelated behaviors and weight status. Obes. doi:10.1002/oby.22372

25. Kiefner-Burmeister A, Hinman N (2020) The role of general parenting style in child diet and obesity risk. Curr Nutr Rep. doi:10.1007/s13668-020-00301-9

26. Langer SL, Seburg E, JaKa MM, Sherwoord NE, Levy RL (2017) Predicting dietary intake among children classified as overweight or at risk for overweight: independent and interactive effects of parenting practices and styles. Appetite. doi:

10.1016/j.appet.2016.12.011

27. Blissett J, Hayraft E (2008) Are parenting style and controlling feeding practices related? Appetite. doi:10.1016/j.appet.2007.10.003

Page $14 / 17$ 
28. Pratt M, Hoffmann D, Taylor M, Musher-Eizenman D (2017) Structure, coercive control, and autonomy promotion: a comparison of fathers' and mothers' parenting strategies. J Health Psychol. doi:10.1177/1359105317707237

29. Hendy HM, Williams KE, Camise TS, Eckman N, Hedemann A (2009) The parent mealtime action scale (PMAS). Development and association with children's diet and weight. Appetite. doi:10.1016/j.appet.2008.11.003

30. Jansen E, Smith K, Thapaliya G, Sadler J, Aghababian A, Carnell S (2022) Associations of mothers' and fathers' structure-related food parenting practices and child food approach eating behaviors during the COVID pandemic. Physiol Behav. doi:10.1016/j.physbeh.2022.113837

31. Wolf EJ, Harrington KM, Clark SL, Miller MW (2013) Sample size requirements for structural equation models: an evaluation of power, bias, and solution propriety. Educ Psychol Meas. doi:10.1177/0013164413495237

32. Whitaker C, Stevelink S, Fear N (2007) The use of Facebook in recruiting participants for health research purpose: a systematic review. J Med Internet Res. doi: 10.2196/jmir.7071

33. Baltar F, Brunet I (2012) Social research 2.0: virtual snowball sampling method using Facebook. Internet Res. doi: $10.1108 / 10662241211199960$

34. Ahorsu DK, Lin C, Imani V, Saffari M, Griffiths MD, Pakpour AH (2020) The fear of COVID-19 scale: development and initial validation. Int J Ment Health. doi: 10.1007/s11469-020-00270-8

35. Ritchie LD, Fitzpatrick MA (1990) Family communication patterns: Measuring intrapersonal perceptions of interpersonal relationships. Commun Res. doi: 10.1177/009365090017004007

36. Koerner AF, Schrodt P, Fitzpatrick MA (2017) Family communication: Patterns theory a grand theory of family communication. In: Engaging Theories in Family Communication: Multiple Perspectives. Taylor and Francis; 1980. P. 142-153. doi:10.4324/9781315204321

37. Birch LL, Fisher JO, Grimm-Thomas K, Markey CN, Sawyer R, Johnson SL (2001) Confirmatory factor analysis of the child feeding questionnaire: a measure of parental attitudes, beliefs and practices about child feeding and obesity proneness. Appetite. doi:10.1006/appe.2001.0398

38. Guerrero AD, Chung PJ (2015) Racial and ethnic disparities in dietary intake among California children. J Acad Nutr Diet. doi: 10.1016/j/jland.2015.08.019

39. Niebylski ML, Redburn KA, Duhaney T, Campbell NR (2015) Healthy food subsidies and unhealthy food taxation: A systematic review of the evidence. Nutr. doi:10.1016/j.nut.2014.12.010

40. Cartwright M, Wardle J, Steggles N, Simon AE, Croker H, Jarvis MJ (2003) Stress and dietary practices in adolescents. Health Psychol. doi:10.1037/0278-6133.22.4.362

41. Lopez NV, Schembre S, Belcher BR, O'Conner S, Maher J, Arbel R, Margolin G, Dunton GF (2018) Parenting styles, food-related parenting practices, and children's healthy eating: a mediation analysis to examine relationships between parenting and child diet. Appetite. doi:10.1016/j.appet.2018.06.021

42. MacKinnon DP, Lockwood CM, Hoffman JM, West SG, Sheets V (2002) A comparison of methods to test mediation and other intervening variable effects. Psychol. doi: 10.1037/1082-989X.7.1.83

43. Kline R (2016) Principles and practice of structural equation modeling, 4th edn. The Guilford Press, New York

44. Allison PD (2003) Missing data techniques for structural equation modeling. J Abnorm Psychol. doi: 10.1037/0021-843X.112.4.545

45. Muthen BO (2005) Negative variance. http://www.statmodel.com/discussion/messages/14/300.html?1376598279 Assessed October 11, 2020. Assessed 11 Oct 2022

46. Alm S, Olsen SO, Honkanen P (2015) The role of family communication and parent's feeding practices in children's food preferences. Appetite. doi: 10.1016/j.appet.2015.02.002

47. Koerner AF, Fitzpatrick MA (2006) Family communication patterns theory. A social cognitive approach. In Braithwaite DO, Baxter LA, Engaging theories in family communication: Multiple perspectives. Sage Publications; p.50-65

48. Perry C. Silver, Linings(2021) : Positive Effects of the COVID-19 Pandemic on Children.Parents. https://www.parents.com/kids/health/childrens-mental-health/silver-linings-positive-effects-of-the-covid-19-pandemic-on-children/ Assessed 21 Nov 2021.

49. Birch LL, Davison KK (2001) Family Environmental Factors Influencing the Developing Behavioral Controls of Food Intake and Childhood Overweight. Pediatr Clin North Am. doi:10.1016/S0031-3955(05)70347-3

50. Birch LL, Fisher JO (1998) Development of eating behaviors among children and adolescents. Pediatr PMID:12224660 
51. Fisher JO, Mitchell DC, Smiciklas-Wright H, Birch LL (2002) Parental influences on young girls' fruit and vegetable, micronutrient, and fat intakes. J Am Diet Assoc PMCID:PMC2530939

52. Yee AZH, Lwin MO, Ho SS (2017) The influence of parental practices on child promotive and preventive food consumption behaviors: a systematic review and meta-analysis. Int J Behav Nutri. 2017; doi: 10.1186/s12966-017-0501-3

53. Gallo LA, Gallo TF, Young SL, Moriz KM, Akison LK (2020) The impact of isolation measures due to COVID-19 on energy intake and physical activity levels in Australian University students. Nutrients. doi:10.3390/nu12061865

54. Ruíz-Roso MB, de Carvalho Padilha P, Matilla-Escalante DC, Brun P, Ulloa N, Acevedo-Correa D, Arantes Ferreira Peres W, Martorell M, Rangel Bousquet Carrilho T, de Oliveira Cardoso L et al (2020) Changes of Physical Activity and Ultra-Processed Food Consumption in Adolescents from Different Countries during Covid-19 Pandemic: An Observational Study. Nutrients. ; doi: 10.3390/nu12082289

55. Schaeffer K, Among US (2019) couples, women do more cooking and grocery shopping than men.

https://www.pewresearch.org/fact-tank/2019/09/24/among-u-s-couples-women-do-more-cooking-and-grocery-shopping-than-men/ Assessed 21 Nov 2021.

56. Desert locust risk maps - (2020) Food and Agricultural Organization of the United Nations.

https://www.fao.org/ag/locusts/en/archives/1340/2517/2518/index.html Assessed 18 Nov 2022.

\section{Figures}

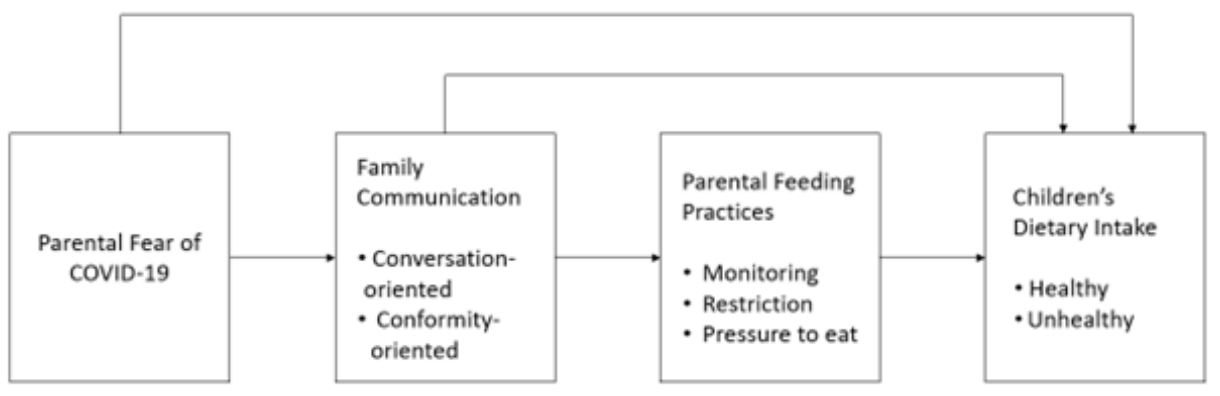

\section{Figure 1}

Hypothesized Model

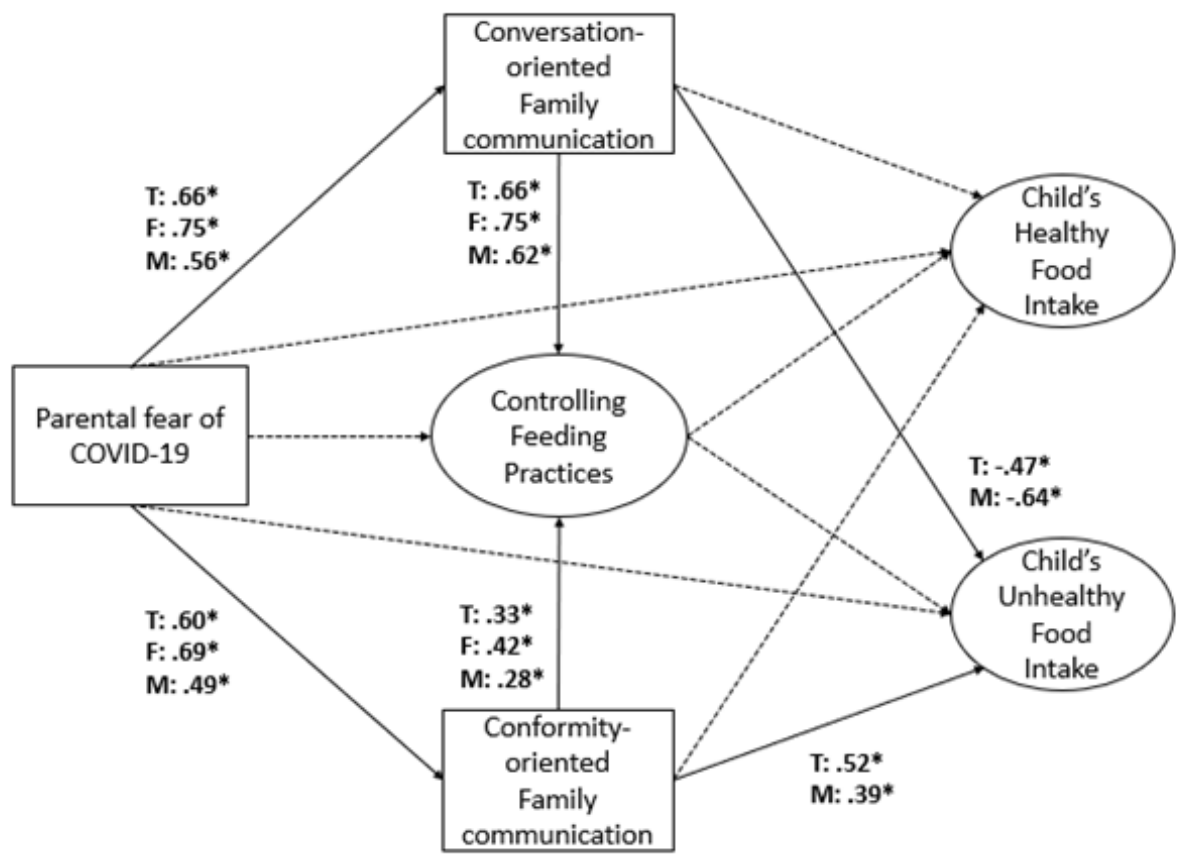

Figure 2

Page $16 / 17$ 
Final model with significant standardized path coefficients marked with solid lines ( $\left.{ }^{\star} p<.05\right)$. Child's gender was entered as a control variable. Ellipses and rectangles represent unobserved latent and observed variables, respectively. Dashed line indicates a nonsignificant path.

T: Total sample, F: Fathers, M: Mothers. 